\title{
CONTROLE DAS PLANTAS DANINHAS NA CULTURA DE ALFACE TRANSPLANTADA COM O HERBICIDA OXADIAZOMI')
}

\author{
EDISON MARTINS PAULO(2), MAMOR FUJWARAM • TAKASHI NISHIDAM
}

\begin{abstract}
RESUMO
Efetwou-se um experimento com o herbicida oxadiazom, objetivando estudar o efeito do seu uso no controle das plantas daninhas e na produça da cultura da alface transplantada. Os tratamentos, em número de sete, consistiram em tes doses de oxadiazom formulado em granulos, 1,0, 1,5 e $2,0 \mathrm{~kg} / \mathrm{ha}$, aplicadas apos 0 transplante da alface, dois tratamentos de $1,0 \mathrm{~kg} / \mathrm{ha}$ do herbicida formulado em concentrado emulsionavel, um putverizado antes e, outro, após o tansplante, em área total, e duas testemunhas, uma capinada e outra mantida com o mato at a colheit. As principais plantas daninhas que infestaram o experimento foram: beldroega (Portulacca okracea L.), picăo-branco (Galinsoga parvilora Cav.), caruru (Amaranthus hibridus L.), capim-colchăo (Digiteria sanguinalis (L.) Scop.) e capim-pé-de-galinha (Eleusine indica (L.) Gaertn.). Constatou-se o controle dessas espécies pelo oxadiazom, 51 dias apos a aplicaçăo, ate que se mostrou seletivo a cultura, exceto na sua formulaçáo concentrado emulsionável pulverizada após 0 transplante, quando reduziu 0 número 8 peso das alfaces colhidas.
\end{abstract}

Tormos de indexaçăo: alfece, oxadiazom, plantas daninhas.

\section{ABSTRACT \\ WEED CONTROL IN TRANSPLANTED LETTUCE BY OXADIAZON}

A trial was carried out in order to study the performance of oxadiazon on yield of transplanted lettuce. The treatments were: oxadiazon granular

(1) Trabalho recebido para publicação em 17 de janeiro e aceito em 31 de agosto de 1990.

(2) Estação Experimental de Agronomia da Alts Paulista, Instituto Agronómico (IAC), Caixa Postal 28, 13001 Campinas (SP).

(1) Seção de Irrigação e Drenagem (IAC).

(4) Rhodia Agro S.A. 
formulation at rates of $1.0,1.5$ and $2.0 \mathrm{~kg} / \mathrm{ha}$ applied after tansplanting and preemergence of weeds; oxadiazom emulsifiable concentrate at $1.0 \mathrm{~kg} / \mathrm{ha}$ applied before and after transplanting both as preemergence of weeds. Two controls were used: one without any control of weeds and another free from weeds 33 days after tsansplanting. Oxadiazon gave good control of Portulacca oleracea L., Galinsoga parvifora Cav., Amaranthus hibriotus L., Digitaria sanguinalis (L.) Scop. and Eleusine indica (L.) Gaerth. up to 51 days after application. Except for oxadiazon emulsifiable formulation, when applied after tansplanting, no phytotoxicity to lettuce was observed with the herbicide whether applied at preemergence or before transplanting. The treatment with the emulsifiable formulation showed severe reduction on number and vield of harvested lettuce.

Index terme: lettuce, oxadiazon, weods.

\section{INTRODUÇÃO'}

As plantas daninhas competem com as cultivadas pelos fatores de sobrevivencia - água, nutrientes, luz e $\mathrm{CO}_{2}$ - concorrendo para a diminuiçāo da produtividade agricola. Na cultura da alface, BAZAN \& CASTILLO (1979) verificaram que o período crftico de competição ocorre entre $021^{\circ}$ e $056^{\circ}$ dia após o transplante. APPEZZATO et al. (1983), em nossas condiç̋̋es, obtiveram resultados indicativos de que o mato deve ser eliminado no transcorrer das primeiras tes semanas apos o transplante das mudas no campo. Por meios mecanizados, essa prática 6 dificultada pelo espaçamento reduzido da alface. Na cultura, o uso de herbicidas năo 6 muito difundido. Os poucos ingredientes ativos a ela seletivos (WEED SCIENCE SOCIETY OF AMERICA, 1983) Am ainda rara comercializaçăo no Brasil.

O oxadlazom é um herbicida que atua por contato, afetando a reglão de crescimento das plantas daninhas quando estas, na sua emergéncia, atravessam a camada de solo com ele tratada WEED SCIENCE SOCIETY OF AMERICA, 1983). Esse produto tem mostrado eficiencla no controle de infestantes mono- $\theta$ dicotiledôneas $\theta$ uso promissor em algumas culturas transplantadas (MENGES \& TAMEZ, 1981; DEUBER \& AGUIAR, 1982; PAULO ot al., 1984). Dentre as suas características, destacam-se pouca llxiviação (PAULO et al., 1979) o vida média de dois a cinco meses (MENGES \& TAMEZ, 1981), as quais tornam apropriada sua aplicaçăo em solos intensamente cultivados e submetidos a laminas freqüentes de Irrigação, como os da cultura da alface.

O presente trabalho objetivou estudar o efeito do oxadiazom no controle das plantas daninhas na produção da cultura da alface.

\section{MATERIAL E MÉTODOS .}

O ensaio foi instalado no Centro Experimental de Campinas, do Instituto Agronómico, em maio de 1984, em um latossolo vermelho-amarelo, textura argilosa, cujas caracteristicas quimicas são as seguintes: $\mathrm{pH}$ em $\mathrm{CaCl}_{2}=5,3$; 
M.O. $=3,8 \% ; \quad P=322 \mu \mathrm{g} / \mathrm{cm}^{3} ; \quad K=0,31 ; \quad \mathrm{Ca}=8,9 ; \quad \mathrm{Mg}=1,0 ; \mathrm{H}+\mathrm{Al}=$ $=3,0 \mathrm{meq} / 100 \mathrm{~cm}^{3} \mathrm{eV}=77 \%$. Adotou-se o delineamento experimental de blocos ao acaso com sete tratamentos e quatro repetições. A alface (Lactuca sativa $L$ ) cultivar Aurélia foi transplantada 25 dias após a semeadura no espaçamento 0,20 $\times 0,25 \mathrm{~m}$ para parcelas com as dimensoes de $1,10 \mathrm{~m}$ de largura $e 2,10 \mathrm{~m}$ de comprimento. Considerou-se a área útll de $0,5 \mathrm{~m}^{2}$ ocupada por dez plantas estabelecidas no centro das unidades experimentais. Constituíram os tratamentos as doses 1,0, 1,5 e 2,0kg/ha do oxadiazom [2-tert-butyl-4-(2,4-dichloro-5-lsopropoxyphenil) - $\Delta^{2}-1,3,4-0 x a d i a z o m-5$-one] formulado em grânulos, dols tratamentos de $1,0 \mathrm{~kg} / \mathrm{ha}$ do oxadlazom formulado em concentrado emulsionável e duas testemunhas sem herbicida: uma, livre das plantas daninhas a partir dos $\mathbf{3 3}$ dlas do transplante da alface $\theta$, outra, mantida com o mato até a colhelta. Aplicou-se a formulaçäo granulada após o transplante, evitando-se o contato dos gránulos com as folhas da alface. As doses da formulaçăo concentrado emulsionável foram aspergidas em área total, uma pulverizada antes $\theta$, outra, depois do transplante da alface, com um pulverizador manual e à pressão de $3,15 \mathrm{~kg} / \mathrm{cm}^{2}$ mantida constante por injeçāo direta de $\mathrm{CO}_{2}$ no tanque do equipamento, consumindo-se 250 litros de calda por hectare. O herbicida fol aplicado na pré-emergéncia das plantas daninhas.

Durante o perlodo experimental, procederam-se às seguintes avaliações:

a) Contagem $e$ identificaçăo botânica das plantas daninhas presentes em dois anos de $0,25 \mathrm{~m}^{2}$, localizados ao acaso no terço médio das parcelas (IGUE et al., 1982), decorridos 33 e 51 dias da aplicação do herbicida;

b) Número e peso fresco das alfaces colhidas aos 65 dias do transplante.

\section{RESULTADOS E DISCUSSÃO}

As principais plantas daninhas que infestaram o experimento foram as seguintes: beldroega (Portulacca oleracea L) ; picão-branco (Galinsoga parvifiora Cav.); caruru (Amaranthus hibridus LL); capim-colchăo (Digitaria sanguinalis (L) Scop.) e capim-pé-de-galinha (Eleusine indica (L.) Gaertn.). Essas espécies apresentaram $100 \%$ de freqüéncia no tratamento mantido com 0 mato até a colheita da alface $\theta$ constituíram cerca de $85 \%$ da vegetação espontânea total. Suas densidades populacionais em cada um dos tratamentos nas avaliaçóes realizadas 33 e 51 dias após a aplicaçăo do herbicida encontram-se, respectivamente, nos quadros 1 e 2.

Comparando-se os tatamentos quimicos com a testemunha mantida com o mato ate a colheit da alface, nota-se que o capim-colchāo, capim-pe-de-galinha, caruru e beldroega foram efetivamente controlados por todas as doses do oxadiazom durante o perfodo experimental, confirmando as observaç⿰丿㇅口 de DEUBER \& AGUIAR (1982) e PAULO et al. (1984). Entretanto, năo se verifica o controle do picäo-branco pelo herbicida 33 dias apos a aplicaçăo (Quadro 1). Tal resultado, que discorda dos desses autores, pode ser explicado pelo intervalo de quatro dias decorridos entre o término do preparo dos cantairos para o plantio da 
alface e a aplicaçāo do oxadiazom. Nesse período, as sementes iniciaram o processo de germinação e emergiram antes que o herbicida estivesse em concentração suficiente na solução do solo para exercer sua açăo. Essa hipótese 6 corroborada pelo controle do picão-branco, observado na maioria dos tratamentos, na leitura aos 51 dias após a aplicaçăo do oxadiazom (Quadro 2). 0 mesmo argumento pode ser atribuido para o menor controle da beldroega na dose $1,0 \mathrm{~kg} / \mathrm{ha}$ do herbicida formulado em granulos aos 33 dias da aplicaçăo (Quadro 1) e sua melhor eficiencia aos 51 dias (Quadro 2), em relaçāo as maiores doses estudadas. Tentativamente, pode-se inferir dos resultados obtidos que, em uma escala crescente de sensibilidade ao herbicida, tem-se: picão-branco < beldroega < capim-colchäo = capim-pé-de-galinha = caruru, considerando-se o infcio da germinação dessas espécies ao mesmo tempo.

Nas avaliaçōes efetuadas - Quadros 1 e 2 - o número total de plantas daninhas diminuiu significativamente $\theta$ linearmente segundo o aumento da dose do oxadiazom em grânulos. Observa-se ainda que a dose $1,0 \mathrm{~kg} / \mathrm{ha}$ em concentrado emulsionável tendeu a ser mais eficiente no controle total das plantas daninhas do que a mesma dose em granulado. A explicação para isso reside no modo de aplicação da soluçāo aquosa através da pulverização, cujo método permite a distribuiçāo mais uniforme de doses baixas do produto sobre o solo, 0 que dificilmente 6 conseguido com a aplicação manual da formulaçåo granulada. HOROWIZ (1966), estudando o diclobenil em granulos, verificou que a expansão lateral desse herbicida năo foi proporcional ao número de granulos por unidade de área. A expansão lateral do oxadiazom em grânulos, na sua menor dose, deve ainda ter sofrido limitaçōes em virtude de ser o produto fortemente adsorvido pela materia orgânica e pelos colóides minerais do solo (PAULO et al., 1979).

A atividade herbicida do oxadiazom, constatada ate 51 dias após a aplicaçăo - Quadro 2 - está de acordo com a vida média do ingrediente ativo, de dois a cinco meses, relatada por MENGES \& TAMEZ (1981). Esse período abrange aquele em que as plantas daninhas necessitam ser eliminadas da cultura da alface, quer nas primeiras tres semanas logo a seguir ao transplante (APPEZZATO et al., 1983), quer na fase do $21^{\circ}$ ao $56^{\circ}$ dia após a colocação das mudas no campo (BAZÁN \& CASTILLO, 1979).

O número $e$ o peso das alfaces colhidas por tratamento são apresentados no quadro 3. Nota-se que as testemunhas năo diferiram estatisticamente entre si no peso das alfaces colhidas, embora a capinada a partir dos 33 dias do transplante tenha mostrado tendencia a expressar maior produção do que a mantida com mato até a colheita. Esse resultado concorda com o obtido por BAZAN \& CASTILLO (1979), porém não com o observado por APPEZZATO ot al. (1983). APPEZZATO et al. (1983) verificaram, no tratamento onde a alface ficou live das infestantes após as primeiras cinco semanas do transplante, produção significativamente maior em relação àquele onde a vegetaçăo espontánea permaneceu at a colheita. A discordancia pode ter tido como causa a eliminação das diversas plantas daninhas presentes nos aros utilizados nas avaliaçöes da flora infestante dos tratamentos. Dessa forma, aos 33 e 51 dias após o transplante, realizou-se tamberm, na testemunha mantida com o mato ate a colheita, a monda em $21,6 \%$ da área total das parcelas, o que, associado a baixa densidade populacional daninha ocorrida no experimento, deve ter influenciado o resultado. 


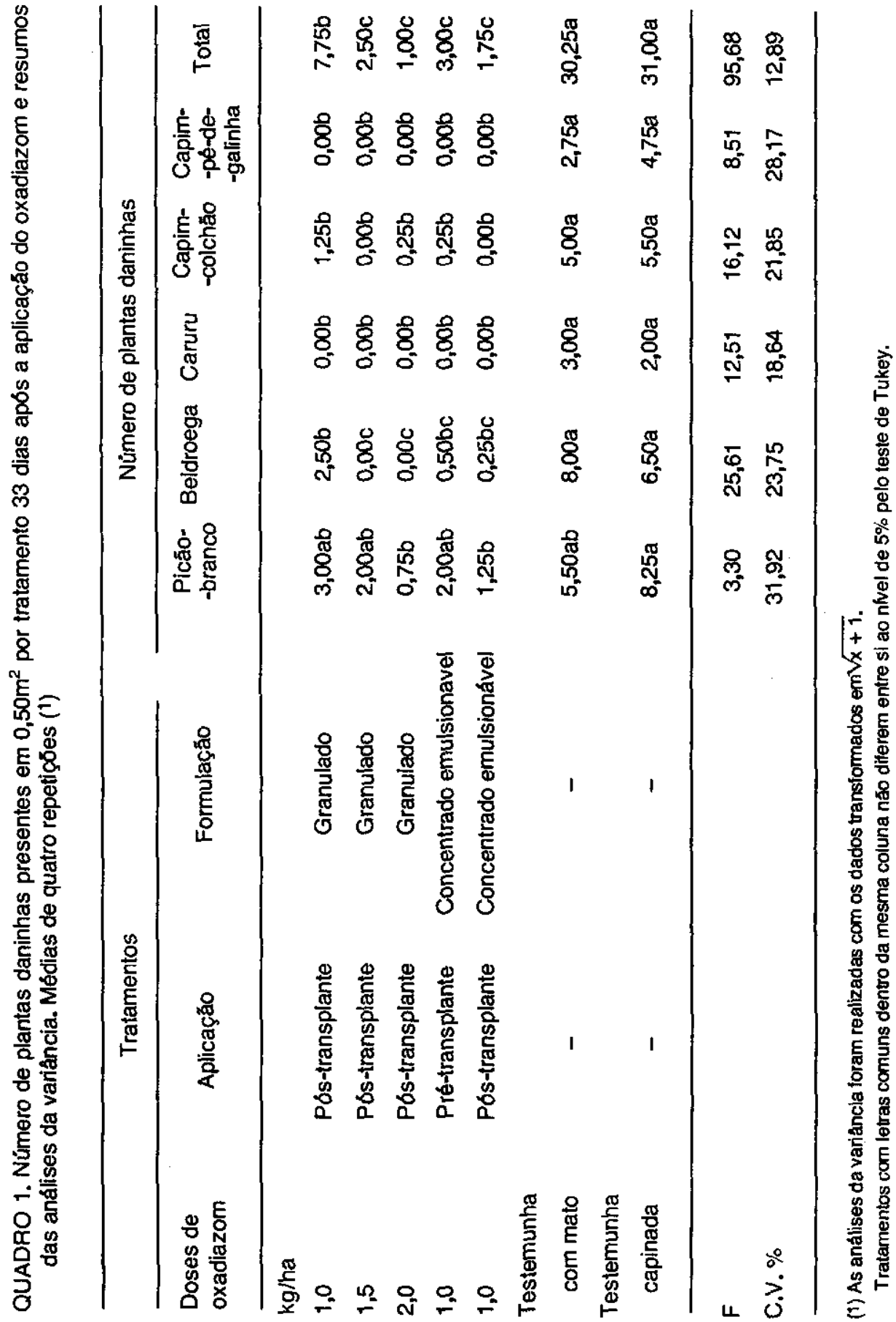




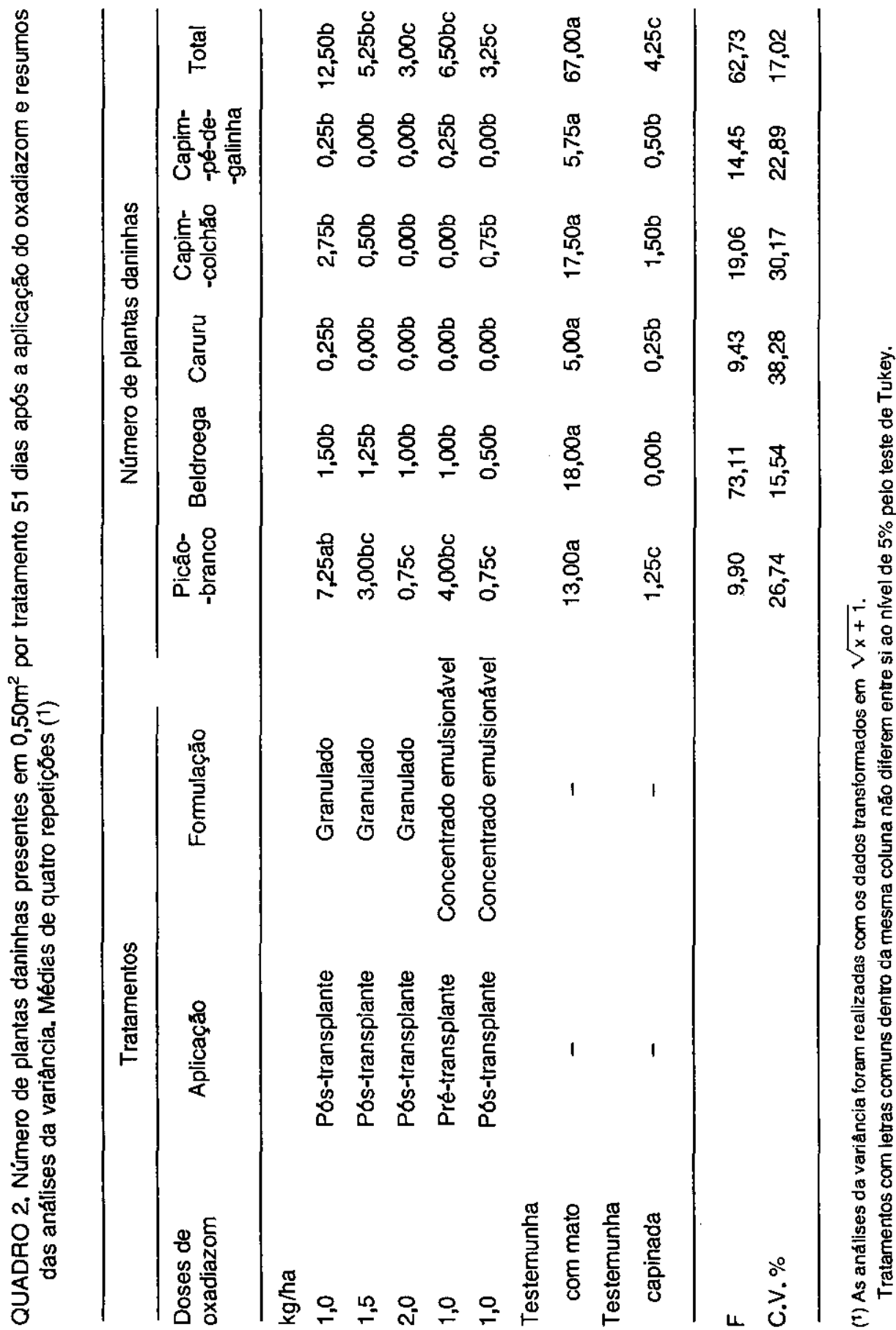




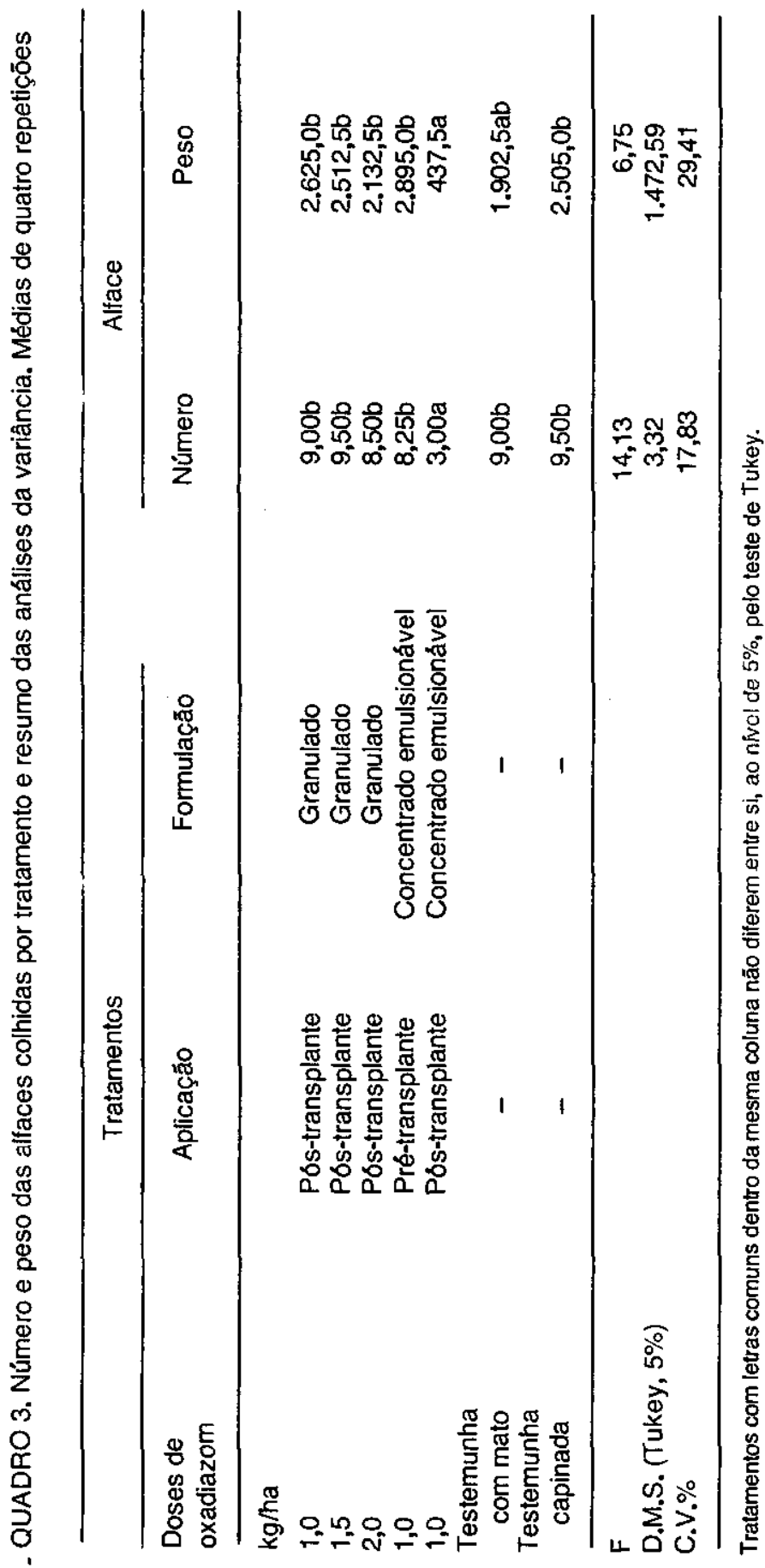


Nota-se que, embora sem diferenças significativas, as alfaces tenderam a ter menor peso conforme aumentou a dose do oxadiazom. Entretanto, somente a formulação concentrado emulsionável do herbicida pulverizada após o transplante conferiu toxicidade a essa olerácea e diminuiu drasticamente o peso e o número de alfaces colhidas. Os demais tratamentos químicos a testemunha capinada não diferiram estatisticamente entre si nos fatores de produção avaliados, o que revela a seletividade do oxadiazom a cultura, se aplicado em grânulos após o transplante ou em concentrado emulsionável antes do transplante da alface.

\section{CONCLUSÕES}

1. O oxadiazom mostrou-se seletivo à cultura da alface quando aplicado em granulos após o transplante ou pulverizado antes do transplante da olerácea.

2. O oxadiazom reduziu drasticamente o número $\theta 0$ peso das alfaces colhidas quando pulverizado apos o seu transplante.

3. O oxadiazom, em todas as doses estudadas, controlou efetivamente o capim-colchão, o capim-pe-de-galinha, 0 caruru $\theta$ a beldroega.

\section{REFERÊNCIAS BIBLIOGRÁFICAS}

APPEZZATO, B.; TERAO, D.; CHRISTOFOLETI, P.J.; PIEDADE, S.M. de S.; VICTORIA FILHO, R. \& MINAMI, K. Competção de plantas daninhas com a cultura da alface (Lactuca sativa cv. Babá). O Solo, Piracicaba 75(2):5-10, 1983.

BAZÁN, L.C. \& CASTILLO, W.P. Periodo crítico de competição das plantas daninhas com a alface (Lactuca sativa L. cv. White Boston. In: CONGRESSO BRASILEIRO DE OLERICULTURA, 19., Florianópolis, 1979. Resumos. Florianópolis, EMPASC, 1979. v.1, p.126-129.

DEUBERK, R. \& AGUIAR, J.C. Uso de oxadiazon em culturas de crisântemos (Chrysantemum sp.) e rosas (Rosa sp.). In: CONGRESSO BRASILEIRO DE HERBICIDAS E PLANTAS DANINHAS, 14., C CONGRESO DE LA ASOCIACIÓN LATINOAMERICANA DE MALEZAS, 6., Campinas, 1982. Resumos. Campinas, 1982. p.157.

HOROWIZ, M. Experiments with granules of Dichlobenil under glasshouse condition. Weed Research, Oxford, 6:91-103, 1966.

IGUE, T.; PAVEZI, R.T. \& PAULO, E.M. Estudo de amostragem em experimentos com herbicidas. Planta Daninha, Piracicaba, 5(2):14-19, 1982.

MENGES, R.M. \& TAMEZ, S. Response of onion (Alium cepa) to annual weeds and postemergence herbicides. Weed Science, Ithaca, 29(1):74-79, 1981. 
PAULO, E.M.; FUJIWARA, M. \& AGUIAR, J.C. Oxadiazon nas culturas da couve, da couve-flor $a$ do tomate. In: CONGRESSO BRASILEIRO DE HERBICIDAS E PLANTAS DANINHAS, 15., CONGRESO DE LA ASOCIACIÓN LATINOAMERICANA DE MALEZAS, 7., Belo Horizonte, 1984. Resumos. Belo Horizonte, 1984. p.154.

; SIGNORI, L.H. \& DEUBER, R. Lixiviação de Metribuzin, Oxadiazon e Bromacil em dois tipos de solo. Planta Daninha, Piracicaba, 2(2):111-115, 1979.

WEED SCIENCE SOCIETY OF AMERICA. Herbicide Handbook. 50.ed.. Champaign, 1983. p.356-359. 